ARTIGO

\title{
O ensino integrado como medida política em prol da justiça social: o caso dos cursos EFA em Portugal e do PROEJA no Brasil
}

\author{
Rosanna Maria Barros Sál (D) \\ Dante Henrique Moura" (D \\ Ana Lucia Sarmento Henrique"(®
}

\section{RESUMO}

Com base em referencial sociocrítico, reflete-se sobre duas políticas educacionais destinadas à educação de jovens e adultos em Portugal e no Brasil que ilustram a possibilidade de o Estado assumir seu papel de garantir o direito à educação. Conclui-se que esses cursos voltam-se para a formação do educando, propiciando-lhe tanto o direito de acesso ao conhecimento historicamente construído como a uma profissionalização que the permita atuar no mundo do trabalho e na produção de sua subsistência. No entanto, em um movimento que compromete sua existência, esses cursos são afetados por decisões ou políticas advindas do governo embasadas em pressupostos contrários àqueles que os fundamentam. Além disso, uma macroanálise mostra que a posição ideológica da governança estatal define as decisões relativas à educação.

PALAVRAS-CHAVE

educação de jovens e adultos; cursos EFA, Portugal; PROEJA, Brasil. 


\title{
INTEGRATED EDUCATION AS A POLICY MEASURE FOR SOCIAL JUSTICE: THE CASE OF AET COURSES IN PORTUGAL AND PROEJA IN BRAZIL
}

\begin{abstract}
Based on a socio-critical framework, we reflect on two educational policies aimed at youth and adult education in Portugal and in Brazil, which illustrate the possibility of the State assuming its role of guaranteeing the right to education. It is concluded that these courses focus on the formation of students, providing them with both the right of access to historically constructed knowledge and a professionalization that allows them to act in the world of work and in the production of their subsistence; and, on the other hand, in a movement that compromises their existence, these courses are affected by government decisions or policies based on assumptions contrary to their foundations. A macro-analysis also shows that the ideological position of State governance is what defines decisions related to education.
\end{abstract}

KEYWORDS

youth and adult education; AET courses, Portugal; PROEJA, Brazil.

\section{ENSEÑANZA INTEGRADA COMO ACCIÓN POLITICA EN FAVOR DE LA JUSTICIA SOCIAL: EL CASO DE LOS CURSOS EFA EN PORTUGAL Y EL PROEJA EN BRASIL}

\section{RESUMEN}

Desde un marco sociocrítico, se reflexiona sobre dos políticas educativas dirigidas a educación de jóvenes y adultos, en Portugal y en Brasil, que ilustran la posibilidad de que el Estado asuma su función de garantizar el derecho a la educación. Se concluye que estos cursos, por un lado, se centran en la educación del estudiante, brindándole tanto el derecho de acceso al conocimiento construido históricamente como a una profesionalización que le permite operar en el mundo del trabajo y la producción de su subsistencia; y, por otro lado, en un movimiento que compromete su existencia, estos cursos se ven afectados por decisiones o políticas gubernamentales basadas en supuestos contrarios a sus fundamentos. Además, un macroanálisis muestra que la posición ideológica de la gobernanza estatal define las decisiones educativas. 


\section{A CIDADANIA UNIVERSAL, A JUSTIÇA SOCIAL E O DIREITO DOS JOVENS E ADULTOS À EDUCAÇÃO}

Inicialmente, é importante discutir o significado e os limites dos termos desse título diante da hegemonia mundial do capitalismo. Esse modo de produção, por se nutrir da desigualdade entre as classes sociais, subalternizando a classe trabalhadora à burguesia, é em sua essência incompatível com a justiça social em seu sentido pleno, ou seja, o direito de todos e de todas de produzir, de forma equânime, a sociedade e a própria existência por meio do controle social e coletivo dos meios de produção. Pelos mesmos motivos, a cidadania e o direito à educação são também limitados na sociedade capitalista.

Nesse sentido, a discussão que se segue sobre cidadania e direito dos jovens e adultos à educação ocorre nos marcos da sociedade capitalista, pois essa forma de sociabilidade humana é hoje hegemônica e, para sua superação, é imprescindível compreender em profundidade o seu funcionamento, para que se possa engendrar um novo modo de a humanidade produzir sua existência. Nesse contexto, é preciso pensar o capitalismo como uma construção histórica da humanidade e, portanto, que pode ser histórica e socialmente superada por outra forma de produção da existência.

Foi a complexificação da sociedade capitalista e a agudização das desigualdades sociais por ela produzida a partir, principalmente, do início do século XX que trouxeram à tona a questão social como um problema a ser resolvido pelo Estado. Assim,

[...] a intervenção estatal via políticas sociais, regulando e/ou propiciando condições de manutenção e reprodução de uma parcela da população, é considerada uma função intrínseca ao Estado moderno, configurando padrões de direitos sociais próprios a cada nação. (Fleury, 1994, p. 11)

A partir daí se foi construindo a noção de cidadania como um conjunto de direitos e deveres dos indivíduos perante o Estado, os quais são proporcionados à população com maior ou menor intensidade, dependendo da correlação das forças políticas que disputam a direção desse Estado. Mas importa-nos destacar que a intervenção estatal por meio de políticas sociais é uma das evidências do caráter contraditório do capitalismo, pois, ao atuar apenas em seus efeitos destrutivos, tal intervenção contribui para a "potencialização e agudização da contradição básica desse modo de produção entre a socialização das forças produtivas e a apropriação privada da riqueza social" (Fleury, 1994, p. 11).

Fleury (1994) trata de três grandes modelos por meio dos quais os Estados-nação constituem as redes de proteção social, proporcionando o acesso da população a direitos sociais como educação, saúde, moradia, transporte, segurança e alimentação: a assistência social, o seguro social e a seguridade social.

Embora nenhum dos três modelos se proponha a romper com a lógica do capital, o terceiro, mesmo circunscrito a essa lógica, é o que tem maiores possibilidades de tencionar algumas características e fundamentos desse sistema, como a intrínseca e natural desigualdade entre os seres humanos, apregoada pelo pensamento liberal, 
que nutre o capitalismo. Esse modelo, diferentemente dos outros dois, tem como fundamento norteador a garantia da universalização de um conjunto de direitos sociais no domínio da renda, dos bens e dos serviços a todos os cidadãos, por meio de políticas sociais decorrentes da ação centralizada e unificada do Estado, que financia e administra o sistema. Para a autora,

Reconhece-se, neste modelo de política social, o predomínio da relação de $C i$ dadania Universal, além de um padrão de intervenção governamental que busca conjugar políticas econômicas e sociais como partes indissociáveis da mesma estratégia desenvolvimentista. (Fleury, 1994, p. 110)

O modelo seguridade social, ao assumir a defesa do atendimento centralizado e universal dos cidadãos no que se refere aos direitos sociais, opera em sentido contrário a esse fundamento do capitalismo e, portanto, sua materialização pode produzir avanços significativos na direção de uma efetiva justiça social. É exatamente por isso que esse modelo não consegue se concretizar plenamente nas diversas regiões do planeta, especialmente nas zonas não centrais do capitalismo mundial, caso de Portugal e do Brasil, embora com características distintas.

Nesse sentido, a União Europeia é um dos principais polos do capitalismo mundial, mas o rendimento, por pessoa, das famílias portuguesas se situa significativamente abaixo dos países de capitalismo mais avançado da União Europeia. Por exemplo, se adotarmos o rendimento das famílias portuguesas como 100, em 2014, encontramos que, nesse mesmo ano, o da Suíça foi 171,6; o da Alemanha, 163; o da França, 145,6; e o do Reino Unido, $132,1 .{ }^{1}$ Apenas Grécia e os países com ingresso mais recente na União Europeia tiveram indicador inferior ao de Portugal.

De outro modo, o Brasil é um país central na América Latina, que não está situada entre os principais polos do capitalismo mundial. Por exemplo, o Brasil tem o maior produto interno bruto (PIB) da América Latina e do Caribe. Segundo Gremaud (2017), em 2015 o PIB brasileiro representou 33,6\% do total dessa região, seguido do México (21,6\%) e da Argentina (12\%). Já em PIB per capita, o dos brasileiros (US $\$ 11.164,40)$ não se situa entre os mais elevados, suplantado pelo PIB de países de menor economia, como Bahamas (US\$20.683,90) e Trinidade e Tobago (US\$16.684,50).

A rápida análise desenvolvida nos permite situar Portugal e Brasil, em termos econômicos, respectivamente, na periferia do centro e no centro da periferia do capitalismo mundial. Diante dessa relação entre centro e periferia nos dois países, discutiremos de forma sintética como vem sendo proporcionado e/ou negado o acesso à educação aos jovens e adultos nesses países.

Em Portugal, país central na geopolítica mundial por vários séculos, a garantia da educação como direito de todos e de todas, embora exista legalmente, não foi concretizada. Nesse contexto, em 1911,70,3\% da população era analfabeta; em 1950, esse índice era de 40,4\%. O PORDATA informa que, em 1970, 25,7\% de pessoas

1 Disponível em: https://gz.diarioliberdade.org/portugal/item/18850-centro-e-periferias-na-europa-portugal-um-caso-de-desastre-periferico.html. Acesso em: 5 abr. 2018. 
eram analfabetas; em 1991, 11\%; e, em 2011, 5,2\%. Os dados evidenciam, por um lado, um grande esforço no intuito de garantir o acesso da população à educação fundamental, mas, por outro lado, também ressalta que a realidade concreta impediu a universalização desse direito.

Quando transferimos o foco de análise para a educação secundária, a situação se agrava, pois, em 2017, 52,2\% da população entre 25 e 64 anos não haviam concluído essa etapa da educação. Enquanto isso, esse índice para a União Europeia foi de 22,6\%, no mesmo ano.

No Brasil, a lógica secular de uma sociedade escravocrata veio produzindo exclusões em todas as esferas, inclusive na educacional, o que se agudiza com a consolidação do capitalismo como modo de produção hegemônico em escala planetária. Nesse contexto, os índices de analfabetismo no país sempre foram muito elevados entre os segmentos mais empobrecidos da sociedade (Haddad e Del Pierro, 2000).

No início do século passado, $72 \%$ da população acima de 5 anos era analfabeta e, em 1960, esse mesmo índice era de 46,7\% (Haddad e Del Pierro, 2000). Dados mais recentes (IBGE, 2016) informam que a taxa de analfabetismo brasileira é de $7,2 \%$ (11,8 milhões de pessoas), sendo maior entre os homens $(7,4 \%)$ que entre as mulheres $(7,0 \%)$ e desigual entre as regiões: maior no Nordeste $(14,8 \%)$ e menor no Sul $(3,6 \%)$, o que desvela a manutenção de um verdadeiro apartheid social.

Se deslocamos a análise da alfabetização para níveis mais elevados de escolarização, o quadro se agrava. Ainda segundo o IBGE (2016), 73,5\% da população acima de 25 anos não concluiu o ensino médio, última etapa da educação básica no Brasil e equivalente ao ensino secundário em Portugal, legalmente obrigatória para todos e pré-requisito para o acesso ao ensino superior.

A análise até aqui empreendida nos permite concluir que a relação de proximidade/distanciamento dos países do centro/periferia tem relação muito próxima com a garantia do direito à educação da população em geral e, em particular, aos sujeitos jovens e adultos. No caso específico de Portugal (periferia do centro) e do Brasil (centro da periferia), os dados mostram duas realidades preocupantes e com certo grau de aproximação (que pode ser decorrência do fato de o Brasil já ter sido colônia portuguesa), embora a periferia do centro apresente uma realidade melhor do que a do centro da periferia.

\section{A PERSPECTIVA COMPARADA NA INVESTIGAÇÃO EM EDUCAÇÃO DE JOVENS E ADULTOS}

O nosso modelo de análise adotado na comparação está ancorado em uma abordagem crítica da agenda política para a educação de jovens e adultos, que articulou a perspetiva do sistema mundial com a perspetiva sócio-histórica, para, assim, analisar aspectos da realidade educacional contemporânea.

Nesse enquadramento, entendemos que a comparação na educação de jovens e adultos ajuda a explicitar questionamentos diversos na área da educação desde que se mantenha clara a historicidade do objeto estudado (Rezende, Isobe e Moreira,2013). Ou seja, trata-se de procurar interpretar a singularidade dos fenômenos sem perder de vista 
as suas relações com a conjuntura social mais ampla, o que implica situar os discursos e práticas para explicitar melhor aquilo que é singular (Bray, Adamson e Mason, 2007).

Diante do exposto, este texto procurou discutir duas práticas selecionadas por contribuírem, embora com tensões e contradições, para aumentar, nos respetivos contextos nacionais estudados, a justiça social e educacional para jovens e adultos pouco escolarizados. Foi nossa pretensão problematizar as agendas políticas implementadas tanto em Portugal quanto no Brasil, discutindo algumas proximidades e distanciamentos entre essas duas realidades, mas deixando emergir, quer as semelhanças contextualizadas, quer as particularidades históricas.

Acreditamos que daqui resultam pistas para melhor interpelar as tensões e os conflitos ideológicos que envolvem as políticas portuguesas e brasileiras de educação de jovens e adultos em um cenário de crescente controle panótico sociopolítico e educacional, que se desenvolve hoje no âmbito de complexos processos de erosão política dos Estados nacionais no contexto de globalização neoliberal. Isto é, entendemos que nessa conjuntura de transnacionalização, que aporta novas lógicas para a regulação e a governação educacional (Barros, 2019), se está processando uma ressignificação dos processos educacionais que envolvem jovens e adultos, o que implica um desafio à atividade científica para se engajar na procura de novos ângulos de análise do fenômeno educacional. Trata-se, pois, de procurar novas condições de comparabilidade nos objetos de estudo (Souza e Martinez,2009) ao mesmo tempo em que se procuram novas pontes no âmbito das redes sociais internacionais de investigação criadas pelos cientistas sociais críticos para instituir novos sentidos e espaços interpretativos na produção de conhecimento sobre educação, porque nem a ciência nem a educação podem já ser concebidas em um quadro estritamente nacional (Wallerstein, Lemert e Rojas, 2013).

\section{PRÁTICAS EM PROL DA JUSTIÇA SOCIAL: O CASO DOS CURSOS DE EDUCAÇÃO E FORMAÇÃO DE ADULTOS EM PORTUGAL}

Na história da educação de jovens e adultos em Portugal,é possível identificar a continuidade de uma invariante estrutural: a persistente ausência de uma política para esse âmbito, que possa ser caraterizada simultaneamente por ser pública, global, integrada, continuada, autônoma e democraticamente governada (Melo, 2005). Com efeito, é notável as constantes hesitações por parte da ação estatal no domínio da promoção de retaguarda educacional para uma população adulta com níveis inadmissíveis de iliteracia(s) em contexto democrático (Benavente et al., 1995), postura que conduziu à afunilada rede pública desse setor ${ }^{2}$ existente à data da comemoração do Ano Europeu da Aprendizagem ao Longo da Vida. ${ }^{3}$ Em certa

2 Desde 1986, altura em que emerge a Lei de Bases do Sistema Educativo (Portugal, 1986), a rede pública desse setor era afunilada porque estava baseada apenas na oferta de ensino recorrente, ou seja, de segunda oportunidade. Trata-se de uma realidade que só seria alterada a partir de 2001.

3 Para saber mais, ver: https:/eur-lex.europa.eu/legal-content/EN/TXT/?uri=LEGISSUM:c11024. Acesso em: 20 mar. 2020. 
medida, motivadas por esse marco da governação educacional europeia (Barros e Belando-Montoro, 2013), surgem preocupações em nível nacional com a situação depauperada da educação de jovens e adultos enquanto subsistema público de educação, anunciando-se, em 1996, o seu relançamento com o novo estatuto de opção estratégica da política educativa (Barros, 2013).

Assim, foi o Programa de Ação S@ber+: Programa para o Desenvolvimento e Expansão da Educação e Formação de Adultos, 1999-2006, que veio apresentar e disseminar uma nova concepção para o setor, agora entendido enquanto

conjunto das intervenções que, pelo reforço e complementaridade sinérgica com as instituições e as iniciativas em curso no domínio da educação e da formação ao longo da vida se destinam a elevar os níveis educativos e de qualificação da população adulta e a promover o desenvolvimento pessoal, a cidadania activa e a empregabilidade. (Melo, Matos e Silva, 2001, p. 11)

Essa moldura de fundo comportou a nova estratégia de promoção da "articulação entre os domínios da educação, formação e emprego, através do reconhecimento dos processos de aprendizagem não formais, nomeadamente os ligados aos contextos de trabalho" (Melo, Matos e Silva, 2001, p. 6), sobretudo porque

o essencial do problema, em particular na população não jovem, é simultaneamente de qualificação profissional e de capacitação escolar. Logo, é preciso encontrar respostas articuladas entre o trabalho que se faz no domínio da educação ao longo da vida, e o que se faz na formação profissional contínua. (Pedroso in Melo, Matos e Silva, 2001, p. 9)

Em outras palavras, considerou-se que "tem de haver respostas integradas, e as entidades têm de se articular: aquilo que significa avanço profissional tem de ser também avanço em termos de educação, de formação geral da pessoa" (Melo, Matos e Silva, 2001, p. 11).

Com essa visão de base, que se aproxima do modelo de seguridade social (Fleury, 1994), o Programa de Ação S@ber+ apresentou um conjunto de objetivos ${ }^{4}$ que orientaram os seus três eixos de intervenção: aumentar a motivação das pessoas adultas para a procura de cursos; criar uma oferta adequada, flexível e diversificada de educação e formação, por parte das entidades formadoras; e promover a formação de agentes. Destacamos o segundo eixo, que visou diversificar a oferta apostando na promoção de múltiplas articulações com sistemas já existentes, tais como o sistema de formação profissional, o sistema escolar e o sistema nacional de certificação. Desse eixo de intervenção resultaria um novo sistema de educação e formação de

4 Sublinham-se os objetivos gerais de apoiar ações capazes de estruturar e ampliar a oferta; de realizar projetos em uma lógica, quer de serviço público, quer de parceria; de sensibilizar a opinião pública para a necessidade da aprendizagem ao longo da vida; de definir elencos de competências-chave; de assegurar o reconhecimento e a validação das competências adquiridas e desenvolver novos modelos, metodologias e materiais de intervenção pedagógica e socioeducativa (Melo, Matos e Silva, 2001, p. 12-13). 
adultos, de estrutura modelar centrado no reconhecimento, validação e certificação dos resultados da autoformação da população adulta, tendo sido priorizada para tal a criação das estruturas necessárias para permitir que os adquiridos experienciais fossem alvo de uma "análise rigorosa e reconhecimento formal, traduzidos numa validação oficial: creditação (outorga de créditos) com equivalência, parcial (dispensa de uma certa parte do percurso de formação) ou total (certificação, obtenção imediata de diploma oficial)" (Melo, Matos e Silva, 2001, p. 33).

Desse modo, foram promovidas em Portugal, a partir de 2001, práticas que se destinariam essencialmente para atender à situação educacional da população ativa ${ }^{5}$ mediante a "criação de soluções flexíveis que articulem a educação e a formação, através de percursos organizados, a partir de processos de reconhecimento e validação de saberes adquiridos e de sistemas modulares de formação" (ANEFA, 2001a, p. 29). Portanto, a par do já existente no ensino recorrente de adultos (ERA), básico e secundário, e da educação extraescolar (EEE), a estruturação da nova oferta de educação e formação de adultos compreende, a partir desse período, as seguintes modalidades: oferta de cursos de educação e formação de adultos (cursos EFA); uma oferta de Ações S@ber+ e oferta de Reconhecimento, Validação e Certificação de Competências (RVCC). Como resultado dessas políticas públicas efetivadas se viria a constatar um real alargamento da rede nacional referente ao setor e, portanto, uma expansão da diversificação da oferta, apesar da excessiva concentração de esforços numa parcela da população adulta: a população ativa.

Assim, no tocante à oferta de cursos EFA, criados com a finalidade de proporcionar a redução dos elevados índices de subqualificação,${ }^{6}$ o que sobressaiu como mais característico e inovador foi a sua concepção em uma lógica de dupla certificação, ${ }^{7}$ escolar e profissional, com base em um modelo — que se quis integrado — baseado num referencial de competências-chave dividido por áreas ${ }^{8} \mathrm{e}$ de acordo com o princípio transversal de iniciar cada curso EFA apoiado no reconhecimento e

5 Tratando-se de um universo de cerca de 4.700.000 ativos em que, segundo dados de 1998 do Ministério do Trabalho e Solidariedade, "cerca de 2.400.000 não possuem o 90 ano de escolaridade, sendo que 30\% dos ativos são semi ou não qualificados, isto é, têm uma formação inferior ao nível III de qualificação profissional” (ANEFA, 2001a, p. 29).

6 Na justificação estratégica desses cursos, apresentada no Plano de Atividades da Agência Nacional de Educação e Formação de Adultos (ANEFA) para 2001, pode-se ler: "A diversificação e a flexibilização das ofertas de educação e formação de adultos, sobretudo as destinadas à população com mais baixos níveis de qualificação escolar e profissional, mantém-se, em 2001, um imperativo que a ANEFA assume como uma das prioridades da sua intervenção [...] face à posição que Portugal ocupa relativamente aos restantes países da União Europeia no que concerne aos índices de escolarização e qualificação da sua população, e face, também, ao agravamento dessa posição nos últimos anos" (ANEFA, 2001b, p. 41).

7 A dupla certificação é concebida nos termos do despacho conjunto n. 1.083/2000, de 20 de novembro.

8 No Referencial de Competências-Chave do Ensino Básico, as áreas eram e ainda são: Cidadania e Empregabilidade (CE), Linguagem e Comunicação (LC), Matemática para a Vida (MV) e Tecnologias de Informação e Comunicação (TIC) (ANEFA, 2002c). 
na validação das competências adquiridas previamente por cada adulto-formando. ${ }^{9}$ Tratou-se, no essencial, de procurar instituir um novo ponto de partida ${ }^{10}$ para os processos pedagógicos que envolvem os adultos, ambicionando-se superar "a dupla herança" (Canário in ANEFA, 2002a, p. 50) que vinha caracterizando a história recente da educação de jovens e adultos em Portugal, nomeadamente a da vertente escolarizante, que persistia no ensino recorrente de adultos, e a vertente da formação profissional, tendente a reproduzir uma perspectiva funcionalista da relação entre a formação e o trabalho. De acordo com Canário,

estas duas tradições situam-se nos antípodas de uma formação que se pretende baseada na centralidade do sujeito que aprende, a partir do reconhecimento e validação de adquiridos experienciais e tendo como referência não uma listagem de conteúdos, mas sim um conjunto alargado de competências a construir. (Canário in ANEFA, 2002a, p. 50)

Nesse sentido, toda a concepção curricular dos cursos EFA, então inovadora no setor, ${ }^{11}$ envolveu um sistema modular criado "numa perspectiva de individualização e diferenciação dos trajetos de educação-formação, incluindo componentes integradas de formação profissionalizante e de formação de base que possibilitem a obtenção de uma certificação única" (ANEFA, 2002b, p. 7-8) em um dos três níveis de certificação, ${ }^{12}$ com que o projeto-piloto dos cursos EFA começaria a ser implementado no contexto português. $\mathrm{O}$ balanço público resultante da análise dos primeiros 13 cursos EFA em observação foi apresentado em 2002 como globalmente positivo, encorajando "o alargamento e consolidação progressivos deste novo tipo de oferta educativa, dirigido a públicos adultos não escolarizados, ou cuja escolarização não cobre a educação básica obrigatória" (Canário apud ANEFA, 2002a, p. 49).

9 A especificidade dos destinatários particularizaria essa oferta, concebida para "adultos pouco qualificados, muitas vezes em risco de exclusão social, [cursos] numa perspetiva de construção de novas relações sociais, interativas e de empowerment, capazes de proporcionar a esses adultos a construção dos seus próprios projetos de vida pessoais e profissionais" (ANEFA, 2002a, p. 12).

10 Pretendeu-se que esses cursos EFA respondessem à necessidade de conseguir uma "maior e melhor articulação entre a educação e a formação, sem que a primeira ignore a segunda e sem que a segunda colonize a primeira, afunilando-se em formação profissional de banda estreita" (Santos Silva, 2002, p. 73).

11 Essa nova orientação metodológica para os cursos EFA seria o resultado, afirma-se, da "procura de uma solução formativa efetivamente capaz de propor um modelo mais consentâneo com a natureza dos adultos e de escapar à lógica escolar do currículo [pelo que] a ANEFA concebeu uma organização curricular pelas competências que, numa perspetiva mais ampla e englobante, devem ser entendidas como 'saberes em ação e para a ação" (ANEFA, 2002b, p. 6).

12 No final do percurso formativo assim efetuado, seria possível ao adulto a obtenção de um certificado de EFA, que poderia ser de três tipos: básico 1 (B1), equivalente ao $1^{\circ}$ ciclo do ensino básico e ao nível I de qualificação profissional; básico 2 (B2), equivalente ao $2^{\circ}$ ciclo do ensino básico e ao nível I de qualificação profissional; ou básico 3 (B3), equivalente ao $3^{\circ}$ ciclo do ensino básico e ao nível II de qualificação profissional. 
Efetivamente, os cursos EFA foram ampliados, sendo possível a obtenção de certificação para o ensino secundário ${ }^{13}$ (12 anos de escolaridade) por essa via a partir de 2007. Desde então foram implementados diversos reajustes ${ }^{14}$ em sua organização, diversificando-se a oferta de esquemas de formação flexíveis, ${ }^{15}$ mas articulados, sendo possível aos adultos maiores de 18 anos obter uma dupla certificação (escolar e profissional) ou apenas uma delas. ${ }^{16}$ Ora, os cursos EFA obedecem aos referenciais de competências-chave ${ }^{17}$ e de formação associados às respetivas qualificações constantes do Catálogo Nacional de Qualificações e são agrupados por áreas de educação e formação, de acordo com a Classificação Nacional das Áreas de Educação e Formação.

Em suma, o fato de os cursos EFA ofertarem uma trajetória personalizada e flexível, assente nos resultados de uma avaliação diagnóstica ou no reconhecimento e validação de competências adquiridas ao longo da vida, e de promoverem no percurso momentos de avaliação formativa que culminam numa avaliação somativa final aproxima essa oferta ao tipo de práticas capazes de contribuir para a criação de um mundo melhor, ou seja, justo e democrático, afinal esse é o primeiro e último desiderato de uma concepção de educação de adultos ampla e criticamente orientada.

Não obstante, é possível identificar a presença de um hibridismo nas orientações da política educativa para o setor, de 2001 até o momento atual, que também aqui combina, como sustentam Teodoro e Aníbal, para a educação em geral, "discursos de pendor construtivista numa perspetiva crítica com discursos apologistas de eficiência social que submete a utilidade da educação à produtividade económica" (Aníbal e Teodoro, 2008, p. 105). Trata-se de um hibridismo gerador de tensões e de contradições diversas também no campo das práticas, que espelham a intermitência com que se atribui importância ou não à agenda política para a educação de jovens e adultos. Oscilações nas ações do governo têm mantido intacta a caraterística macroestrutural da agenda política para a educação de jovens e adultos em Portugal desde 1974: uma aposta dos governos de esquerda (Partido Socialista) entrecortada pelo abandono político dos governos de direita (Partido Social-Democrata).

13 Despacho n. 11.203/2007, de 8 de junho.

14 Portaria n. 230/2008, de 7 de março; portaria n. 711/2010, de 17 de agosto; portaria n. 283/2011, de 24 de outubro; e portaria n. 216-C/2012, de 18 de julho.

15 Para a educação de base estão disponíveis os percursos formativos B3 (1.940 horas) e B2+B3 (2.390 horas). Para a educação secundária estão disponíveis os percursos formativos S3, tipos A (2.045 horas), B (1.680 horas) ou C (1.575 horas); ou os percursos formativos $\mathrm{S}$, tipos A (1.150 horas), B (625 horas), ou C (315 horas).

16 Por se tratar de um curso EFA de dupla certificação, é concedido um certificado de conclusão no $3^{\circ}$ ciclo do ensino básico ( $9^{\circ}$ ano de escolaridade) e o nível II do Quadro Nacional de Qualificações (QNQ), ou certificado de habilitações do ensino secundário (12 ${ }^{\circ}$ ano de escolaridade) e o nível IV do QNQ. Para saber mais, consultar: http://www. catalogo.anqep.gov.pt/. Acesso em: 20 mar. 2020.

17 No referencial de competências-chave do nível secundário, as áreas são: Cidadania e Profissionalidade (CP), Cultura, Língua e Comunicação (CLC) e Sociedade, Tecnologia e Ciência (STC) (DGFV, 2006). 


\section{PRÁTICAS EM PROL DA JUSTIÇA SOCIAL: O CASO DO PROEJA NO BRASIL ${ }^{18}$}

A história da educação de jovens e adultos no Brasil pode ser estudada considerando a premissa de que existe regularidade na descontinuidade. É o que evidenciam Haddad e Del Pierro (2000), ao mostrar que historicamente as ações para essa modalidade são desenvolvidas por meio de programas, de campanhas e de projetos fragmentados, ações focais e desarticuladas que não têm garantido o direito dos jovens e adultos à educação na perspectiva de sua universalização. Some-se a isso o fato de a educação profissional no Brasil ser marcada por sua separação da educação básica e por ações que submetem a formação aos interesses imediatos do mercado de trabalho.

O Programa Nacional de Integração da Educação Básica com a Educação Profissional na modalidade de Educação de Jovens e Adultos (PROEJA), ao integrar a educação profissional com a educação básica na modalidade educação de jovens e adultos (EJA), insere-se na histórica descontinuidade das ações dos governos brasileiros para essa modalidade e, conjuntamente, na dualidade histórica que marca a educação profissional. Não por acaso, esse programa passa por redução de incentivos governamentais, além de ter sofrido revezes com a criação do Programa Nacional de Acesso ao Ensino Técnico e Emprego (PRONATEC), com a promulgação da lei n. 13.415/2017, que reformulou o ensino médio brasileiro, e com a instituição do MédioTec, ${ }^{19}$ que transfere parte da responsabilidade das ações educativas do governo em educação profissional para a iniciativa privada, mediante financiamento federal, e incentiva a concomitância em detrimento do ensino médio integrado.

O PROEJA foi instituído com uma dupla finalidade: enfrentar as descontinuidades e o voluntarismo que marcaram a educação de jovens e adultos no Brasil e integrar a educação básica a uma formação profissional que contribuísse para a integração socioeconômica de qualidade dos jovens e adultos na sociedade, contribuindo para a melhoria das condições de participação social, política, cultural e no mundo do trabalho dos jovens e adultos com elevação de escolaridade (Moura e Henrique,2012).

Para tanto, o PROEJA fundamenta-se

[...] na concepção de educação unitária (ensino para a formação integral, geral e técnica, na perspectiva da superação da dualidade entre educação propedêutica e educação profissional) e de educação politécnica ou tecnológica, necessária à compreensão teórica e prática dos fundamentos científicos das múltiplas técnicas utilizadas no processo produtivo. (Regattieri e Castro, 2010, p. 36)

18 Parte das discussões propostas nesta seção foi desenvolvida com base em Henrique (2018).

19 O MédioTec é uma ação do governo federal, por intermédio da Secretaria de Educação Profissional (SETEC), que incentiva a oferta de cursos técnicos de nível médio, na forma concomitante para alunos matriculados no ensino regular, nas redes estaduais e distrital, com repasse de Bolsa Formação às instituições ofertantes. Disponível em: http://portal.mec.gov.br/mediotec. 
Assim, a formação profissional deve estar integrada à educação básica, formando uma totalidade, de forma que possa complementá-la. Em outras palavras, deve organizar-se preferencialmente na forma integrada, embora a concomitante também esteja prevista legalmente.

Com essas bases, entre 2007 e 2011, lentamente, a matrícula pública do PROEJA (federal e estadual; PROEJA Ensino Médio Integrado - PROEJA EMI; e PROEJA Formação Inicial e Continuada - PROEJA FIC Fundamental) cresceu, circunstância que mudou a partir de 2012 em decorrência da criação, em 2011, do PRONATEC, instituído pela lei n. 12.513/2011, conforme apresentado no Quadro 1.

\section{Quadro 1 - Evolução da matrícula do PROEJA Ensino Médio \\ Integrado (2007-2016) e do PRONATEC (2011-2016). ${ }^{20}$}

\begin{tabular}{|c|c|c|c|c|c|c|}
\hline \multirow[b]{2}{*}{ Ano } & \multicolumn{5}{|c|}{ PROEJA Ensino Médio Integrado } & \multirow{2}{*}{$\begin{array}{c}\text { PRONATEC - } \\
\text { cursos técnicos } \\
\text { concomitantes } \\
\text { (Bolsa Formação) }\end{array}$} \\
\hline & Brasil & Federal & Estadual & Municipal & Privado & \\
\hline 2007 & 9.747 & 4.772 & 1.229 & 131 & 3.615 & \multirow{5}{*}{$\begin{array}{c}\text { Não houve matrícula } \\
\text { (programa criado em 2011) }\end{array}$} \\
\hline 2008 & 14.939 & 8.014 & 3.958 & 28 & 2.939 & \\
\hline 2009 & 19.533 & 10.883 & 4.327 & 66 & 4.257 & \\
\hline 2010 & 38.152 & 14.078 & 19.919 & 40 & 4.115 & \\
\hline 2011 & 41.971 & 14.530 & 23.033 & 84 & 4.324 & \\
\hline 2012 & 35.993 & 14.147 & 17.171 & 634 & 4.081 & 109.537 \\
\hline 2013 & 40.117 & 12.801 & 21.909 & 369 & 5.038 & 299.016 \\
\hline 2014 & 42.875 & 11.595 & 19.276 & 429 & 11.575 & 537.159 \\
\hline 2015 & 38.212 & 9.301 & 21.593 & 840 & 6.478 & 103.409 \\
\hline 2016 & 32.710 & 8.282 & 22.120 & 806 & 1.502 & 158 \\
\hline
\end{tabular}

Fonte: Censos da Educação Básica (2007 a 2016) e da Tabela "PRONATEC: total de matrículas por iniciativa e tipo de curso" (Disponivel em: https://portal.ifrn.edu.br/ensino/ppgep/matricula-bolsa-formacao-pronatec. Acesso em: 19 mar. 2020). ${ }^{21}$ Elaboração dos autores.

Se, de um lado, o PROEJA aproxima-se do modelo de seguridade social (Fleury, 1994), de outro, o PRONATEC se distancia desse modelo. Esse programa

20 Os dados oficiais do governo incluem como matrícula do PRONATEC a oferta decorrente da expansão da rede federal de educação profissional, do acordo de gratuidade com o Sistema S e da E-Tec Brasil. Entretanto, essas iniciativas já existiam previamente ao programa, de modo que se optou por incluir apenas as matrículas provenientes da oferta prevista na lei n. 12.513/2011: os cursos proporcionados por meio da Bolsa Formação (cursos técnicos concomitantes e cursos FIC).

21 O link original (painel.mec.gov.br/), acessado em 15 de janeiro de 2019 para a elaboração deste artigo, já não disponibiliza as tabelas referentes à matrícula no PRONATEC, ou seja, as tabelas foram retiradas do site do MEC. Dessa forma, recorremos a uma fonte secundária para que se possa ter acesso aos dados originais. 
opera em sentido contrário às políticas educacionais do campo da educação profissional e da educação de jovens e adultos, incluindo o PROEJA, instituídas pelos Governos Lula. Sua criação ocorreu em meio à proliferação de discursos sobre a necessidade urgente de formação de milhões de trabalhadores em um curto espaço de tempo e da guinada à direita da coalizão política de sustentação do governo brasileiro de então.

O PRONATEC oferece dois tipos de cursos. Aos estudantes das redes públicas estaduais que estão no ensino médio existe a possibilidade de, na forma concomitante, fazerem um curso técnico, em geral, em uma escola do Sistema $\mathrm{S}^{22}$ ou em uma escola privada. Assim, o governo federal transfere recursos à iniciativa privada, mais especificamente às entidades representativas dos interesses do grande capital nacional ${ }^{23}$ para que eles, com esse recurso público, decidam a formação que interessa proporcionar à classe trabalhadora. E evidente que esse tipo de formação não se alinha com a concepção de formação humana assumida no âmbito do PROEJA.

Outra ação do PRONATEC são os cursos de Formação Inicial e Continuada (FIC), com duração mínima de 160 horas, destinados, principalmente, a trabalhadores com baixa escolaridade, que, em grande parte, sequer concluiu o ensino fundamental, ou seja, potencial público da educação de jovens e adultos. Nesse caso, é agravante o fato de que não há uma elevação do nível de escolaridade. Portanto, esses cursos FIC vinculados - pela propaganda - à empregabilidade cooptam a classe trabalhadora e cumprem a função ideológica de legitimar o Estado capitalista, pois as inúmeras certificações criam a ilusão de qualificação para o mercado de trabalho e de melhoria da empregabilidade, o que acaba por convencer a classe trabalhadora de que esses cursos de curta duração lhes são importantes. Entretanto, sua principal função é conformar os trabalhadores aos interesses do capital mantendo a harmonia social (Melo e Moura, 2016, p. 14).

Ideologicamente, percebe-se a subordinação do PRONATEC ao discurso do crescimento econômico e à relação direta (e ilusória) entre qualificação profissional e empregabilidade. Além disso, esse programa incentivou (e incentiva) a expansão da educação profissional pela parceria público-privada, com transferência de recursos para o Sistema S e para outras organizações privadas de educação, e reafirma a dualidade estrutural da educação brasileira pela oferta de cursos técnicos de nível médio na forma concomitante e de cursos FIC aligeirados (Silva, 2015).

Nesse contexto, o Quadro 2 mostra que a matrícula do PROEJA começou a cair significativamente na esfera pública a partir de 2012, ao tempo em que houve extraordinário crescimento da oferta de cursos FIC e técnicos no âmbito do PRONATEC por meio da Bolsa Formação. Entre 2011 e 2014, registrou-se um total

22 O Sistema S é composto por instituições corporativas referentes ao setor produtivo, tais como indústria, comércio, agricultura, transporte que objetivam o treinamento profissional, lazer, consultoria e saúde dos trabalhadores. Embora não seja público, recebe subsídios do governo.

23 Confederações nacionais da indústria, do comércio, da agricultura e dos transportes, mantenedores do Sistema S. 
de 3.336.674 matrículas em cursos FIC e 945.712 matrículas em cursos técnicos, o que evidencia a relação entre o rápido e intenso crescimento da matrícula no âmbito do PRONATEC,$^{24}$ especialmente nos cursos FIC, e a diminuição do esforço nas instituições públicas na oferta do PROEJA. Em consequência, pode-se afirmar que a criação do PRONATEC e sua priorização como política pública vêm produzindo atrofia na oferta de cursos PROEJA.

Quadro 2 - Evolução da matrícula do PROEJA Formação Inicial e Continuada (2007 a 2016) e do PRONATEC (2011 a 2016).

\begin{tabular}{|c|c|c|c|c|c|c|}
\hline \multicolumn{6}{|c|}{ PROEJA Formação Inicial e Continuada Fundamental } & \multirow{2}{*}{$\begin{array}{c}\text { PRONATEC - } \\
\text { cursos Formação } \\
\text { Inicial e } \\
\text { Continuada (Bolsa } \\
\text { formação) }\end{array}$} \\
\hline Ano & Brasil & Federal & Estadual & Municipal & Privado & \\
\hline 2007 & -25 & - & - & - & - & \multirow{4}{*}{$\begin{array}{l}\text { Não houve matrícula } \\
\text { (programa criado em } \\
\text { 2011) }\end{array}$} \\
\hline 2008 & 3.957 & - & - & - & - & \\
\hline 2009 & 3.628 & 55 & 1.559 & 1.766 & 248 & \\
\hline 2010 & 14.126 & 258 & 5.975 & 7.634 & 517 & \\
\hline 2011 & 23.995 & 647 & 14.213 & 8.534 & 601 & 23.180 \\
\hline 2012 & 18.622 & 785 & 11.186 & 6.237 & 414 & 568.293 \\
\hline 2013 & 20.194 & 329 & 13.354 & 6.188 & 323 & 1.361 .245 \\
\hline 2014 & 9.153 & 297 & 4.625 & 4.005 & 226 & 1.383 .956 \\
\hline 2015 & - & - & - & - & - & 193.873 \\
\hline 2016 & - & - & - & - & - & 2.025 \\
\hline
\end{tabular}

Fonte: Censos da Educação Básica (2007 a 2016) e da Tabela "PRONATEC: Total de matrículas por iniciativa e tipo de curso"(Disponível em: https://portal.ifrn.edu.br/ensino/ppgep/matricula-bolsa-formacao-pronatec. Acesso em: 19 mar. 2020). Elaboração dos autores.

Outra medida governamental que trouxe revezes ao PROEJA foi a lei n. 13.415/2017, que reformula o ensino médio brasileiro. Cumpre salientar que essa lei não faz referência direta à modalidade EJA, marginalizando mais uma vez os jovens, adultos, trabalhadores, população do campo, mulheres, negros e pobres, a quem já foi negado o direito de acesso ou de conclusão da educação básica na faixa

24 A diminuição da matrícula no âmbito desse programa, apresentada no Quadro 1 a partir de 2015, justifica-se, entre outros aspectos, pela intensa crise política e econômica imposta ao país desde então.

25 As células em branco (-) correspondem a dados não divulgados pelo Instituto Nacional de Estudos e Pesquisas Educacionais "Anísio Teixeira" (INEP) no respectivo censo. Em 2015 e em 2016, os respectivos censos publicaram a oferta de cursos FIC totalizando os cursos FIC Fundamental e FIC Ensino Médio, de maneira que não foi possível identificar a matrícula exclusiva dos cursos FIC Fundamental. 
etária dita própria ou regular. Entretanto, como a EJA é modalidade do ensino médio, fica também submetida aos princípios gerais emanados dessa lei.

Para Araujo (2018, p. 220),

Por sua abrangência e por seu alcance, essas alterações em um conjunto de leis configuram uma profunda reforma na educação básica nacional, em particular no Ensino Médio, com repercussões sobre as finalidades da educação nacional, sobre a organização curricular dessa etapa de ensino, bem como sobre o trabalho pedagógico, o financiamento da educação básica, o trabalho docente e o futuro profissional dos egressos dessa etapa de ensino.

Além disso, essa lei traz uma concepção restrita de formação humana ao submetê-la às determinações do mercado. Ao tratar do assunto, Saviani (2016) ressalta a concepção estreita de educação que está subjacente à lei n. 13.415/2017. O autor mostra que, ao se deslocar a determinação do currículo dos saberes construídos socialmente e se colocar como cerne dessa definição os objetivos educacionais, então são os objetivos que determinarão os conteúdos que comporão o currículo.

Na visão de Marsiglia et al. (2017, p. 119),

Ao enfatizar as habilidades, as competências, os procedimentos e a formação de atitudes, e ao não destacar os conteúdos escolares, o trabalho educativo e o ensinar, o documento traz uma perspectiva que visa adaptar os alunos ao mercado de trabalho ou, mais propriamente, ao empreendedorismo.

Nessa linha de raciocínio, parte-se daquilo que alegadamente o mercado de trabalho necessita em termos de mão de obra para se definirem competências e habilidades ou "direitos e objetivos de aprendizagem", conforme expresso na lei n. 13.415/2017 (Brasil, 2017a) e na Base Nacional Comum Curricular (BNCC), para se decidir, então, que conteúdos deverão ser objeto do trabalho pedagógico na escola e qual o tempo dessa formação.

Em consequência, percebe-se que a mudança proposta acarretará

o aprofundamento de processos de exclusão dos jovens em situação de maior vulnerabilidade, o aprofundamento das desigualdades sociais, a maior desqualificação da educação básica, principalmente para os mais pobres, e a desvalorização dos profissionais da educação. (Araujo, 2018, p. 220)

Outra medida que caminha na mesma direção é a proposta do MédioTec presencial e na modalidade de educação a distância $(\mathrm{EaD})$, mais uma ação no âmbito do PRONATEC, que separa o ensino médio da educação profissional. Esse programa,

[...] tem como proposta o fortalecimento das políticas de educação profissional mediante a convergência das ações de fomento e execução, de produção pedagógica e de assistência técnica, para a oferta da educação profissional técnica de 
nivel médio articulada de forma concomitante com as redes de educação e com o setor produtivo. (Brasil, 2017b, grifo nosso)

Está explícito no documento que as demandas de formação técnica foram mapeadas em cada uma das cinco regiões do país, para proporcionar mais sinergia entre a demanda e os cursos ofertados, com dados sobre as oportunidades "reais" de inserção, por município, e as aptidões formativas necessárias para atendê-las. É o mercado de trabalho determinando as decisões educacionais, o que contribui para naturalizar a ideia de que a educação é responsável apenas pela aquisição de competências para a empregabilidade.

Se considerarmos que aos sujeitos da educação de jovens e adultos e do PROEJA, com suas trajetórias de interrupções e de retorno à escola, já lhes foi espoliado o conhecimento historicamente construído, sistematizado e acumulado pela humanidade, o Estado, mais uma vez, nega a eles o direito à educação socialmente referenciada. Portanto, a proposta de se materializar no PROEJA as funções reparadora, equalizadora e qualificadora, por meio das quais o Estado tem o dever de assegurar o direito de todos à educação e assim reduzir a desigualdade entre os que tiveram acesso e aqueles aos quais o acesso à escola foi interditado, tende a dar alguns passos atrás.

Em suma, contraditoriamente, de um lado há a instituição do PROEJA, em 2005, que se funda na necessidade de assegurar a formação humana integral aos coletivos aos quais essa formação foi negada e, de outro, as medidas de contenção social, como o PRONATEC, criado em 2011, a reforma do ensino médio e o MédioTec, ambos em 2017, que solapam desses coletivos o direito a essa formação integral por: fomentar cursos de curta duração, sem elevação do nível de escolaridade; por reafirmar a dualidade estrutural da educação brasileira; e por vincular a formação profissional exclusivamente às necessidades do mercado de trabalho.

\section{CURSOS EFA E PROEJA: PONTOS E CONTRAPONTOS}

Antes de discutir especificamente os cursos EFA e o PROEJA, com o objetivo de melhor situar o leitor, são necessárias algumas considerações sobre diferenças conceituais relacionadas com a literatura do campo crítico em Portugal e no Brasil, nomeadamente duas: a concepção de integração curricular e o tratamento analítico dado à pedagogia das competências.

No que concerne à integração curricular na produção acadêmica crítica brasileira, especificamente no caso do ensino médio (ou do ensino fundamental) integrado à educação profissional, objeto central da presente discussão, considera-se que o ensino integrado é a integração entre a denominada educação geral (ciências, letras e artes) e a formação profissionalizante, desenvolvida em um currículo único na mesma instituição educacional, tendo como referência conceitual a formação integral dos sujeitos. Já a literatura portuguesa, conforme discutido anteriormente, considera a integração como sendo a articulação entre as instituições que proporcionam a educação geral básica e aquelas que são 
responsáveis pela formação profissional no sentido de que os sujeitos transitem entre umas e outras visando integrar os conhecimentos gerais e profissionais de modo que possam alcançar a formação integral.

Sobre a pedagogia das competências, existe em Portugal uma perspectiva dominante defensora dessa corrente pedagógica, ${ }^{26}$ sendo minoritário o campo crítico que a desconstrói enquanto corrente político-ideológico-pedagógica conservadora e funcionalista (Barros, 2011; Lima, 1994, 2018). Em consequência, a literatura portuguesa tende a incorporar (acriticamente) o conceito de competência como central nos processos da formação humana, não obstante promulgando-o em uma perspectiva de sua integralidade. Já a literatura crítica brasileira considera a pedagogia das competências contrária à concepção de formação humana integral por considerar que ela está fundamentada nos interesses do mercado de trabalho em detrimento dos sujeitos e da sociedade em sua totalidade. Para os autores brasileiros críticos, o conceito de competência desloca a centralidade da formação humana da relação entre os sujeitos e os processos de produção e aquisição de conhecimentos e de sua participação social, política e econômica, em uma perspectiva de autonomia e emancipação, para o currículo voltado à aquisição de competências subordinadas à empregabilidade (Ramos, 2001). ${ }^{27}$ Feitas essas considerações, passa-se a discutir os cursos EFA e PROEJA.

As duas ações educativas anteriormente caracterizadas e sintetizadas, os cursos EFA, em Portugal, e o PROEJA, no Brasil, foram escolhidas por se aproximarem do modelo de seguridade social (Fleury, 1994), no sentido de que o Estado busca garantir a materialização do direito à educação aliada à formação profissional, de modo que permita a inserção profissional de um contingente de adultos pouco escolarizados. São ações que compreendem a educação de adultos de forma mais ampla e criticamente orientada e a educação como direito igualitário de todos (Barros e Biasin, 2019).

Percebe-se que essas políticas têm em comum sua inscrição em uma história de avanços e retrocessos na agenda educacional prevista para a educação de jovens e adultos. De um lado, avanços nos governos de centro-esquerda entremeados com retrocessos por abandono ou omissão nos governos de direita. Portanto, estar na periferia do centro (caso de Portugal) ou estar no centro da periferia (caso do Brasil) do capitalismo mundial não impede que as decisões relativas à educação passem pelo viés da economia e das necessidades do mercado

26 Contrário a essa posição, de uma perspectiva crítica, o pesquisador português Silva (2006) faz um debate sobre o sentido e o conceito de competência discutindo sua polissemia, sua apropriação por vários campos disciplinares e o foco na ação subjacente a seu significado. Discute ainda a ligação entre o próprio conceito de competência e sua estreita relação com os ideais do neoliberalismo e do neoconservadorismo. Disponível em: http://repositorium.sdum.uminho.pt/handle/1822/8600. Acesso em: 20 mar. 2020.

27 Para maior aprofundamento sobre essa temática, sugere-se ver: Ramos (2001); Fidalgo (2002); Ferretti (2004); Frigotto, Ciavatta e Ramos (2005); Moura, Lima Filho e Silva (2015). 
em consonância com a governança estatal. Essa constatação mostra a intrínseca relação entre as ações educativas e o projeto político-ideológico dos governos.

De um lado, quando se tem a centralidade na dimensão econômica, o papel da educação restringe-se a formar para atender aos interesses do mercado de trabalho. Particularmente, em relação à educação profissional e à educação de jovens e adultos, trata-se de "formar pessoas com a maior competência técnica possível para fazer esse mercado de trabalho funcionar da maneira mais 'aceitável' possível na perspectiva de manter a centralidade na dimensão econômica” (Moura, 2014, p. 32).

De outro lado, quando se tem a centralidade na dimensão do ser humano, a perspectiva formativa, embora não negue a dimensão técnica, não se reduz a ela. Não se despreza a competência técnica, mas a ela integra-se a compreensão da sociedade em que esses sujeitos competentes tecnicamente estão inseridos e das relações de poder a que estão submetidos. Aliado a isso, esses sujeitos "sabem qual o papel da ciência, e a quem interessa determinado tipo de produção do conhecimento, de ciência e de tecnologia, a quem interessam as relações de poder e que dominação existe na sociedade" (Moura, 2014, p. 32).

Saviani (2016), ao apresentar um delineamento do conteúdo curricular da educação básica visando superar os limites da BNCC, argumenta que, caso se pretenda qualificar para o trabalho, promover igualmente o pleno desenvolvimento da pessoa e o preparo para o exercício da cidadania, não basta apenas

alertar contra os perigos da racionalidade técnica advogando-se uma formação centrada numa cultura de base humanística voltada para a filosofia, literatura, artes e ciências humanas à revelia do desenvolvimento das chamadas "ciências duras". É preciso operar um giro da formação na direção de uma cultura de base científica que articule, de forma unificada, num complexo compreensivo, as ciências humano-naturais que estão modificando profundamente as formas de vida passando-as pelo crivo da reflexão filosófica e da expressão artística e literária. (Saviani, 2016, p. 84)

Em comum também nessas duas ações, cursos EFA e PROEJA, são a preocupação com a formação geral do educando integrada à formação profissional e a verticalização nos estudos, concedendo certificação. Nos cursos EFA, a certificação poderia ser de três tipos: básico 1 (B1), equivalente ao $1^{\circ}$ ciclo do ensino básico e ao nível I de qualificação profissional; básico 2 (B2), equivalente ao $2^{\circ}$ ciclo do ensino básico e ao nível I de qualificação profissional; ou básico 3 (B3), equivalente ao $3^{\circ}$ ciclo do ensino básico e ao nível II de qualificação profissional. No caso do PROEJA, tem-se a integralização dos conteúdos da educação básica (fundamental ou médio) integrados a um dos cursos técnicos definidos no Catálogo Nacional de Cursos Técnicos (CNCT). Percebe-se, portanto, preocupação com a formação do educando, propiciando-lhe tanto o direito de acesso (que lhe foi negado) ao conhecimento historicamente construído como uma formação técnica que lhe permita atuar no mundo do trabalho, na produção de sua existência. 
Além disso, analisando essas duas ações, percebe-se que ambas, durante sua execução, sofreram tensões advindas de decisões governamentais ideologicamente contrárias aos pressupostos que as embasavam. Na correlação de forças, na disputa entre projetos de sociedade distintos, outras ações ou políticas de governo enfraqueceram tanto os cursos EFA como os cursos PROEJA, pelo hibridismo nas orientações da política educativa para o setor. Especificamente, no caso do PROEJA, citamos a criação do PRONATEC, do MédioTec, a promulgação da lei n. 13.415/2017 e o silenciamento relativo à modalidade EJA. De um lado, ações educativas fundamentadas em uma perspectiva crítico-social; de outro, ações que submetem a educação à produtividade econômica e cuja função é legitimar o Estado capitalista.

\section{CONCLUSÃO}

As reflexões aqui apresentadas mostram que, apesar do projeto de sociedade hegemônico que alegadamente alinha a educação à empregabilidade, isto é, às necessidades de mercado e à produtividade econômica, é possível pensar e implementar ações educativas que vão na contramão desse projeto. Entretanto, essas ações sofrem intervenções de decisões governamentais que as vão modificando, num processo conflitual de existência e resistência. As aproximações e os distanciamentos recorrentes da educação de jovens e adultos a um paradigma educacional sociocrítico mostra que "a história nunca se fecha por si mesma e nunca se fecha para sempre. São os homens, em grupos e confrontando-se como classes em conflito, que 'fecham' ou 'abrem' os circuitos da história" (Fernandes, 1977, p. 5).

Assim, esses cursos, de um lado, voltam-se para a formação do educando, propiciando-lhe tanto o direito de acesso ao conhecimento historicamente construído como a uma profissionalização que lhe permita atuar no mundo do trabalho e na produção de sua existência, constituindo-se como contributos para a justiça social em sentido pleno; e, de outro, num movimento que compromete sua existência, esses cursos são afetados por decisões ou políticas advindas do governo embasados em pressupostos contrários aos que os fundamentavam e que agravam a desigualdade entre as classes sociais. Ora, é só por um desses caminhos que se potencia o direito à educação da população em geral e, em particular, aos sujeitos jovens e adultos, segundo os parâmetros identificados por Fleury (1994) no modelo de seguridade social.

Percebeu-se, pela análise empreendida, que, mesmo considerando patamares distintos, tanto em Portugal, localizado na periferia do centro, como no Brasil, localizado no centro da periferia do capitalismo mundial, as decisões relativas à educação passam pelo viés da economia e das necessidades do mercado em consonância com a posição ideológica da governança estatal do momento.

Nessa perspectiva, a história dos cursos EFA e PROEJA ilustra a própria história da educação de jovens e adultos, marcada em ambos os países, com certo grau de aproximação, por tensões ideológicas que abrem e fecham os circuitos de sua própria história, ora negando aos sujeitos o direito a uma educação socialmente referenciada, ora se acercando ao marco conceitual de educação de jovens e adultos 
elaborado no Documento de Nairobi (UNESCO, 1976), em que se explicita uma visão integrada na educação e formação como mandato inalienável de desenvolvimento integral do homem e participação no desenvolvimento social, econômico e cultural, de modo equilibrado e interdependente.

\section{REFERÊNCIAS}

ANEFA - Agência Nacional de Educação e Formação de Adultos. Relatório de actividades 2000. Lisboa: ANEFA, 2001a.

ANEFA - Agência Nacional de Educação e Formação de Adultos. Plano de actividades 2001. Lisboa: ANEFA, 2001b.

ANEFA - Agência Nacional de Educação e Formação de Adultos. Relatório nacional - cursos de educação e formação de adultos "em observação" 2000/2001. Lisboa: ANEFA, 2002a.

ANEFA — Agência Nacional de Educação e Formação de Adultos. Cursos de educação e formação de adultos - o modelo de intervenção (B2A). Lisboa: ANEFA, 2002b.

ANEFA - Agência Nacional de Educação e Formação de Adultos. Referencial de competências-chave para a educação e formação de adultos (nível básico). Lisboa: ANEFA, 2002c. Disponível em: http://www.catalogo.anqep.gov.pt/boDocumentos/ getDocumentos/144. Acesso em: 26 mar. 2020.

ANÍBAL, G.; TEODORO, A. A educação em tempos de globalização. Modernização e hibridismo nas políticas educativas em Portugal. In:TEODORO, A. (org.). Tempos e andamentos nas políticas de educação. Estudos Iberoamericanos. Brasília, DF: Liber Livro, 2008. p. 105-122.

ARAUJO, R. A reforma do ensino médio do Governo Temer, a educação básica mínima e o cerco ao futuro dos jovens pobres. HOLOS, Natal, ano 34, v. 8, p. 219-232, 2018. https://doi.org/10.15628/holos.2018.7065

BARROS, R. Genealogia dos conceitos em educação de adultos: da educação permanente à aprendizagem ao longo da vida - um estudo sobre os fundamentos político-pedagógicos da prática educacional. Lisboa: Chiado Editora, 2011.

BARROS, R. As políticas educativas para o sector da educação de adultos em Portugal: as novas instituições e processos educativos emergentes entre 1996-2006. Lisboa: Chiado Editora, 2013.

BARROS, R. The role of transnational bodies in lifelong learning and the politics of measurement: the promise and pitfalls of outcomes-based assessment into recognition of prior learning system in Portugal. In: FINNEGAN, F.; GRUMMELL, B. (eds.). Power and possibility: adult education in a diverse and complex world. Rotterdam: Sense Publishers, 2019. p. 53-63. https://doi. org/10.1163/9789004413320_005

BARROS, R.; BELANDO-MONTORO, M. Europeização das políticas de educação de adultos: reflexões teóricas a partir dos casos de Espanha e Portugal. Education Policy Analysis Archives, Tempe, v. 21, n. 71, p. 1-28, 2013. 
BARROS, R.; BIASIN, C. The right of adults to education: a comparative analysis from the Portuguese and Italian policy agenda. Research in Comparative and International Education, United Kingdom, v. 14, n. 4, p. 1-25, 2019. https://doi. org/10.1177/1745499919881027

BENAVENTE, A.; ROSA, A.; COSTA, A. F.; ÁVILA, P. A literacia em Portugal: resultados de uma pesquisa extensiva e monográfica. Lisboa: Fundação Calouste Gulbenkian; Conselho Nacional de Educação, 1995.

BRASIL. Lei n. 12.513, de 26 de outubro de 2011. Institui o Programa Nacional de Acesso ao Ensino Técnico e Emprego (PRONATEC); altera as leis n. 7.998, de 11 de janeiro de 1990, que regula o Programa do Seguro-Desemprego, o abono salarial e institui o Fundo de Amparo ao Trabalhador (FAT), n. 8.212, de 24 de julho de 1991, que dispõe sobre a organização da Seguridade Social e institui Plano de Custeio, n. 10.260, de 12 de julho de 2001, que dispõe sobre o Fundo de Financiamento ao Estudante do Ensino Superior, e n. 11.129, de 30 de junho de 2005, que institui o Programa Nacional de Inclusão de Jovens (ProJovem); e dá outras providências. Diário Oficial da União, Brasília, DF, 27 out. 2011. Disponível em: http://www.planalto.gov. br/ccivil_03/_Ato2011-2014/2011/Lei/L12513.htm. Acesso em: 14 out. 2019.

BRASIL. Lei n. 13.415, de 16 de fevereiro de 2017. Altera as leis n. 9.394, de 20 de dezembro de 1996, que estabelece as diretrizes e bases da educação nacional, e 11.494, de 20 de junho 2007, que regulamenta o Fundo de Manutenção e Desenvolvimento da Educação Básica e de Valorização dos Profissionais da Educação, a Consolidação das Leis do Trabalho - CLT, aprovada pelo decreto-lei n. 5.452, de $1^{\circ}$ de maio de 1943, e o decreto-lei n. 236, de 28 de fevereiro de 1967; revoga a lei n. 11.161, de 5 de agosto de 2005; e institui a Política de Fomento à Implementação de escolas de ensino médio em tempo integral. Diário Oficial da União, Brasília,DF, 17 fev. 2017a. Disponível em: www. planalto.gov.br/ccivil_03/_ato2015-2018/2017/lei/L13415.htm. Acesso em:17 jul.2017.

BRASIL. Edital Setec n. 01, de 2 de março de 2017. Apresentação de propostas para a oferta de vagas gratuitas em cursos técnicos na forma concomitante, no âmbito do PRONATEC/Mediotec. Brasília, DF: MEC, 2017b. Disponível em: https://www. abmes.org.br/legislacoes/detalhe/2061/edital-setec-mec-n-1. Acesso em: 18 mar. 2020. BRAY, M.; ADAMSON, B.; MASON, M. (eds). Comparative education research: approaches and methods. New York: Springer, 2007.

CANÁRIO, R. Posfácio. In: ANEFA - Agência Nacional de Educação e Formação de Adultos. Relatório nacional - cursos de educação e formação de adultos "em observação" 2000/2001. Lisboa: ANEFA, 2002. p. 49-53.

DGFV - Direcção-Geral de Formação Vocacional. Referencial de competênciaschave para a Educação e Formação de Adultos (nível secundário). Lisboa: ME; DGFV, 2006. Disponível em: http://www.catalogo.anqep.gov.pt/Content/pdfs/ ReferencialRVCCNivel3.pdf. Acesso em: 19 mar. 2020.

FERNANDES, F. Os circuitos da história. São Paulo: Hucitec, 1977.

FERRETTI, C. J. Considerações sobre a apropriação das noções de qualificação profissional pelos estudos a respeito das relações entre trabalho e educação. Educação 
\& Sociedade, Campinas, v. 25, n. 87, p. 401-422,2004. https://doi.org/10.1590/S010173302004000200006

FIDALGO, F. S. A lógica das competências: contribuições teórico-metodológicas para as comparações internacionais. Proposições, Campinas, v. 13, n. 1, p. 111-124, 2002.

FLEURY, S. O Estado sem cidadãos: seguridade social na América Latina. Rio de Janeiro: FIOCRUZ, 1994.

FRIGOTTO, G.; CIAVATTA, M.; RAMOS, M. (orgs.). Ensino médio: concepção e contradições. São Paulo: Cortez, 2005.

GREMAUD, A. Aula 02. A economia latino-americana: situação atual. Curso de Economia da América Latina. Graduação FEARP, 2o semestre 2017. São Paulo: USP, 2017. Disponível em: https://edisciplinas.usp.br/mod/resource/view.php?id=2143169. Acesso em: 30 mar. 2018.

HADDAD, S.; DEL PIERRO, M. C. Escolarização de jovens e adultos. Revista Brasileira de Educação, n. 14, p. 108-130, maio/ago. 2000. Disponível em: http://www. scielo.br/scielo.php?script=sci_arttext\&pid=S1413-24782000000200007\&lng=en\&nr $\mathrm{m}=$ iso. Acesso em: $1^{\circ}$ jun. 2017.

HENRIQUE, A. L. S. O PROEJA e a reforma do ensino médio (lei n. 13.415/2017). HOLOS, Natal, ano 34, v. 3, p. 289-302, set. 2018. Disponível em: http://www2.ifrn. edu.br/ojs/index.php/HOLOS/article/view/7024. Acesso em: 16 jan. 2019. https:// doi.org/10.15628/holos.2018.7024

IBGE - Instituto Brasileiro de Geografia e Estatísticas. PNAD Contínua 2016: 51\% da população com 25 anos ou mais do Brasil possuíam no máximo o ensino fundamental completo. Rio de Janeiro: IBGE, 2016. Disponível em: https://agenciadenoticias. ibge.gov.br/agencia-noticias/2013-agencia-de-noticias/releases/18992-pnad-continua2016-51-da-populacao-com-25-anos-ou-mais-do-brasil-possuiam-apenas-o-ensinofundamental-completo.html. Acesso em: 25 mar. 2018.

INE - Instituto Nacional de Estatística. As edições do Anuário Estatístico de Portugal: 1875 a 2008. Portugal: INE, 2010. Disponível em: https://www.ine. $\mathrm{pt} / \mathrm{xportal} / \mathrm{x}$ main? $\mathrm{xpid}=$ INE\&xpgid=ine_publicacoes\&PUBLICACOESpub_ boui $=100589072 \&$ PUBLICACOESmodo=2\&xlang=pt. Acesso em: 15 mar. 2020.

LIMA, L. C. Modernização, racionalização e optimização. Perspectivas neo-taylorianas na organização e administração da educação. Cadernos de Ciências Sociais, Porto, v. 14, p. 119-139, 1994.

LIMA, L. C. Privatização lato sensu e impregnação empresarial na gestão da educação pública. Currículo sem Fronteiras, [S.l.], v. 18, n. 1, p. 129-144, jan./abr. 2018.

MARSIGLIA, A. C. G.; PINA, L. D.; MACHADO, V. O.; LIMA, M. A Base Nacional Comum Curricular: um novo episódio de esvaziamento da escola no Brasil. Germinal: Marxismo e Educação em Debate, Salvador, v. 9, n. 1, p. 107-121, abr. 2017. http://dx.doi.org/10.9771/gmed.v9i1.21835

MELO, A. Formação de adultos e desenvolvimento local. In: CANÁRIO, R.; CABRITO, B. (orgs.). Educação e formação de adultos: mutações e convergências. Lisboa: EDUCA-Formação, 2005. p. 97-114. 
MELO, A.; MATOS,L.; SILVA, O. S@ber+: programa para o desenvolvimento e expansão da educação e formação de adultos, 1999-2006. Lisboa: ANEFA; GMEFA, 2001.

MELO, T. G. S.; MOURA, D. H. Programa Nacional de Acesso do Ensino Técnico e Emprego (PRONATEC): expansão e privatização da educação profissional. HOLOS, Natal, v. 6, p. 103-119, out. 2016. Disponível em: http://www2.ifrn.edu.br/ojs/index. php/HOLOS/article/view/4995. Acesso em: 15 out. 2019. https://doi.org/10.15628/ holos.2016.4995

MOURA, D.H. A integração curricular da educação profissional com a educação básica na modalidade de jovens e adultos (PROEJA). Cadernos de Pesquisa em Educação, Vitória, v. 19, n. 39, p. 30-49, jan./jun. 2014.

MOURA, D. H.; HENRIQUE, A. L. S. PROEJA: entre desafios e possibilidades. HOLOS, Natal,v. 2, p. 114-129, maio 2012. Disponível em: http://www2.ifrn.edu.br/ ojs/index.php/HOLOS/article/view/914/536. Acesso em: 18 jul. 2017.

MOURA, D. H.; LIMA FILHO, D. L.; SILVA, M. R. Politecnia e formação integrada: confrontos conceituais, projetos políticos e contradições históricas da educação brasileira. Revista Brasileira de Educação, v. 20, n. 63, p. 1.057-1.080, 2015. https:// doi.org/10.1590/S1413-24782015206313

PEDROSO, P. Preâmbulo. In: MELO, A.; MATOS, L,; SILVA, O. S@ber+: programa para o desenvolvimento e expansão da educação e formação de adultos, 1999-2006. Lisboa: ANEFA; GMEFA, 2001. p. 9.

PORDATA. Base de Dados Portugal Contemporâneo. Disponível em: https://www. pordata.pt/Subtema/Portugal/Escolaridade+da+Popula\%c3\%a7\%c3\%a3o-45. Acesso em: 15 mar. 2018.

PORTUGAL. Lei n. 46, de 14 de outubro de 1986. Estabelece o quadro geral do sistema educativo em Portugal. Diário da República, Lisboa: série I, n. 237, 1986. Disponível em: https://dre.pt/application/conteudo/222418. Acesso em: 20 mar. 2020.

PORTUGAL. Despacho conjunto n. 1.083, de 20 de novembro de 2000. Aprova o regulamento relativo à oferta integrada de educação e formação destinada a públicos adultos, a fim de contribuir para a redução do défice de qualificação escolar e profissional . Diário da República, Lisboa: 2a série, n. 268, 2000.

PORTUGAL. Despacho n.11.203, de 8 de junho de 2007. Determina aspetos relativos à organização e funcionamento dos Centros Novas Oportunidades e dos cursos EFA em Portugal. Diário da República, Lisboa: 2a série, n. 110, 2007. Disponível em: https:// www.dgeec.mec.pt/np4/legsigo/\%7B \$clientServletPath\%7D/?newsId=586\&fileNam e=Desp_11203_2007_8junho.pdf. Acesso em: 24 mar. 2020.

PORTUGAL. Portaria n. 230, de 7 de março de 2008. Define o regime jurídico dos cursos de educação e formação de adultos (cursos EFA) e das formações modulares previstos no decreto-lei n. 396/2007, de 31 de dezembro, e revoga a portaria n. 817/2007, de 27 de julho.

Diário da República, Lisboa: Série I, n. 48, 2008. Disponível em: https://dre.pt/ application/conteudo/247246. Acesso em: 24 mar. 2020. 
PORTUGAL. Portaria n. 711, de 17 de agosto 2010. Primeira alteração à portaria n. 230/2008, de 7 de março, que define o regime jurídico dos cursos de educação e formação de adultos (cursos EFA) e das formações modulares previstos no decretolei n. 396/2007, de 31 de dezembro. Diário da República, Lisboa: Série I, n. 159, 2010. Disponível em: https://dre.pt/application/conteudo/342840. Acesso em: 24 mar. 2020.

PORTUGAL. Portaria n. 283, de 24 de outubro de 2011. Segunda alteração à portaria n. 230/2008, de 7 de março, que define o regime jurídico dos cursos de educação e formação de adultos (cursos efa) e das formações modulares previstos no decreto-lei n. 396/2007, de 31 de Dezembro. Diário da República, Lisboa: Série I, n. 204, 2011. Disponível em: https://dre.pt/application/conteudo/146928. Acesso em: 24 mar. 2020.

PORTUGAL. Portaria n. 216-C de 18 de julho de 2012. Primeira alteração à Portaria n. 1100/2010, de 22 de outubro, que aprova o programa de formação em competências básicas em cursos de educação e formação de adultos ou em processos de reconhecimento, validação e certificação de competências de nível básico. Diário da República, Lisboa: 1º Suplemento, Série I, n. 138, 2012. Disponível em: https://dre. pt/application/conteudo/656134. Acesso em: 24 mar. 2020.

RAMOS, M. A pedagogia das competências: autonomia ou adaptação? São Paulo: Cortez, 2001.

REGATTIERI, M.; CASTRO,J.M. Ensino médio e educação profissional: desafios da integração. Brasília, DF: UNESCO, 2010.

REZENDE, V.; ISOBE, R. M.; MOREIRA, F. A. Investigação comparada em educação: aspectos teóricos e metodológicos. Revista Educação e Políticas em Debate, Uberlândia, v. 2, n. 1, p. 229-248, 2013.

SANTOS SILVA, A. Por uma política de ideias em educação. Porto: Edições ASA, 2002. SAVIANI, D. Educação escolar, currículo e sociedade: o problema da Base Nacional Comum Curricular. Movimento: Revista de Educação, Rio de Janeiro, ano 3, n. 4, p. 54-84, 2016. Disponível em: https://periodicos.uff.br/ revistamovimento/article/view/32575/18710. Acesso: 16 mar. 2020. https://doi. org/10.22409/mov.v0i4.296

SILVA, D. M. Desvelando o PRONATEC: uma avaliação política do programa. 2015. 168 f. Dissertação (Mestrado) - Centro de Educação, Universidade Federal do Rio Grande do Norte, Natal, 2015. Disponível em: https://repositorio.ufrn.br/jspui/ bitstream/123456789/20458/1/DanilmaDeMedeirosSilva_DISSERT.pdf. Acesso em: 19 abr. 2018.

SOUZA, D. B.; MARTINEZ, S. A. (orgs.). Educação comparada: rotas de além-mar. São Paulo: Xamã, 2009.

UNESCO - Organização das Nações Unidas para a Educação, a Ciência e a Cultura. Recommendation on the Development of Adult Education - General Conference. Nairobi: UNESCO, 1976.

WALLERSTEIN, I.; LEMERT, C.; ROJAS, C. A. Uncertain worlds: world-systems analysis in changing times. Boulder: Paradigm Publishers, 2013. 


\section{SOBRE OS AUTORES}

Rosanna Maria Barros Sá é doutora em educação pela Universidade do Minho (Portugal). Professora da Universidade do Algarve (Portugal). E-mail:rmbarros@ualg.pt

Dante Henrique Moura é doutor em educação pela Universidad Complutense de Madrid (Espanha). Professor do Instituto Federal de Educação, Ciência e Tecnologia do Rio Grande do Norte (IFRN).

E-mail: dantemoura2014@gmail.com

Ana Lucia Sarmento Henrique é doutora em educação pela Universidad Complutense de Madrid (Espanha).Professora do Instituto Federal de Educação, Ciência e Tecnologia do Rio Grande do Norte (IFRN).

E-mail: ana.henrique@ifrn.edu.br

Recebido em 28 de janeiro de 2019 Aprovado em 4 de dezembro de 2019 